\title{
Influence of semi-trailer truck operating conditions on road surface friendliness
}

\author{
Le Van Quynh \\ Faculty of Automotive and Power Machinery Engineering, Thai Nguyen University of Technology, \\ Thai Nguyen, Vietnam \\ E-mail: lequynhdl@yahoo.com
}

Received 18 October 2017; accepted 27 October 2017

DOI https://doi.org/10.21595/vp.2017.19321

Check for updates

\begin{abstract}
In order to analyze the influence of semi-trailer truck operating conditions on road surface, a three-dimensional vehicle-pavement coupled model with 14 degrees of freedom is established for simulation and calculation. The influence of the different vehicle operating conditions on the dynamic tire loads, dynamic load coefficient (DLC) and road-friendliness which include road surfaces, vehicle speeds, vehicle loads are analyzed in this study. The results shown that the influence of the road surface roughness and vehicle loads on the tire dynamic load coefficient as well as road-friendliness is very obvious. Especially, the DLC values of the 3rd axle increase from $23.97 \%$, and $34.88 \%$ when vehicle moves on three different road conditions with a velocity of $20 \mathrm{~m} / \mathrm{s}$ and fully loaded. Finally, this study result gives the road-friendly limit of driving speed for 5-axle semi-trailer truck when vehicle operates under the different conditions.
\end{abstract}

Keywords: semi-trailer truck, dynamic model, road surface roughness, vehicle speed, vehicle load, dynamic load coefficient.

\section{Introduction}

Semi-trailer trucks play important roles in highway transportation. The early damages caused by heavy load reduce the road service life and ride comfort. Highway maintenance brings huge economic losses, while serious road failure threats traffic safety [1]. The effects of suspension parameters and driving conditions on dynamic load-sharing of longitudinal-connected air suspensions of a tri-axle semi-trailer were investigated comprehensively by Chen Yikai, et al. [3]. A novel nonlinear model of longitudinal-connected tri-axle air suspensions was formulated based on fluid mechanics and thermodynamics and validated through test results. The effects of road surface conditions, driving speeds, air line diameters and connector diameters on the dynamic load-sharing capability of the semi-trailer were analyzed in terms of the DLSC (dynamic load-sharing coefficient) and DLC (dynamic load coefficient). Simulation results indicate that the road-friendliness metric-DLC is not always in accordance with the load-sharing metric-DLSC. The effect of employing larger air lines and connectors on the DLSC optimization ratio gives varying results as road roughness in-creases and as driving speed increases. Based on multi-body dynamics theory, a nonlinear virtual prototype model of heavy duty vehicle (DFL1250A9) is modeled by Yongjie Lu, et al. [4]. Numerical simulation and field test are used to investigate tire dynamic load. Using the reliable model, the effects of vehicle speed, load, road surface roughness and tire stiffness on tire dynamic load and dynamic load coefficient (DLC) are discussed. The results demonstrate that the proposed model can offer efficient and realistic simulation for stochastic dynamic loads, so as to investigate vehicle road-friendliness. A 3D nonlinear dynamic model of a typical heavy truck is developed by Le Van Quynh, et al. [4]. The impact factors of dynamic tire loads are used to evaluate the dynamic interaction between heavy vehicles. The study results provide both the warning limits of road surface roughness and the limits of corresponding dynamic parameters for the 5-axle heavy truck.

In this study, a 5-axle semi-trailer truck with a dependent suspension system for the front axle and a walking beam suspension system for the rear axles is established for analysis and evaluation. The influence of the different vehicle operating conditions on road friendliness which include road surfaces, vehicle speeds, vehicle loads are discussed respectively based on the dynamic tire loads 
and dynamic load coefficient (DLC).

\section{Vehicle dynamic model}

\subsection{Full vehicle dynamic model}

A 5-axle semi-trailer truck with a dependent suspension system for the front axle and a walking beam suspension system for the rear axles are selected for the consideration of road-friendliness. A semi-trailer truck dynamic model with 14 degrees of freedom is established for analyzing the influence of semi-trailer truck operating conditions on road-friendliness, as shown in Fig. 1.

In Fig. $1, K_{i j}$ are the suspension stiffness coefficients; $C_{i j}$ are the suspension damping coefficients; $K_{T k j}$ are the stiffness coefficients of tires; $C_{T k j}$ are the damping coefficients of tires; $M_{1}$ and $M_{2}$ are the sprung mass of the tractor and trailer, respectively; $m_{A i}$ are the unsprung mass of the front axles, respectively; $l_{n}$ and $b_{m}$ are the distances; $z_{a i}$ and $z_{b m}$ are the vertical displacements at the centre gravity of the axles tractor and trailer; $\theta_{k}$ are the angle deflection at the centre gravity of the axles, tractor and trailer; $\varphi_{h}$ are the angle deflection at the centre gravity of tractor and trailer; $v$ is the speed of vehicle; $(i=1,2,3 ; j=r, l ; k=1,2, \ldots, 5 ; n=1,2, \ldots$, $10 ; m=1,2 ; h=1,2,3,4)$.

A combined method of the multi-body system theory and D'Alembert's principle is chosen in this study. The general dynamic differential equation for 5-axle semi-trailer truck is given by the following matrix form:

$M \ddot{z}+C \dot{z}+K z=C_{T} \dot{Q}+K_{T} Q$,

where $M, C, K, C_{T}$ and $K_{T}$ are the mass matrix of the vehicle, damping matrix of the suspension system, stiffness matrix of the suspension system, damping matrix of the wheel system and stiffness matrix of the wheel system, respectively; $z$ is the vector of displacement; $Q$ is the vector of excitation of road surface.

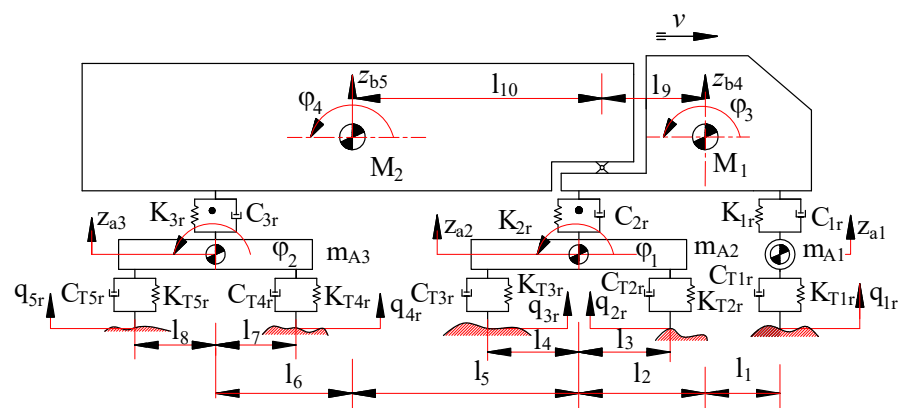

a) Side view

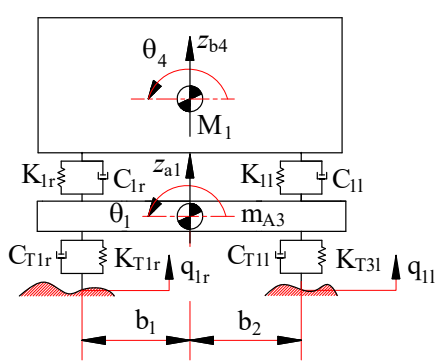

b) Front view

Fig. 1. Vehicle and air suspension system dynamic model

\subsection{Road surface roughness}

The random excitation of road surface roughness can be represented with a periodic modulated random process. The general form of the displacement PSD of the road surface roughness is determined by the experimental formula [5]:

$S_{q}(n)=S_{q}\left(n_{0}\right)\left(n / n_{0}\right)^{-\omega}$,

where space frequency $n$ is the reciprocal of the wavelength $\lambda$. It means wave numbers in a meter. $n_{0}$ is reference space frequency, it's defined as $0.1 \mathrm{~m}^{-1} . S_{q}(n)$ is PSD of road surface under the 
reference space frequency $n_{0}$ known as the road surface roughness coefficient and $\omega$ is the frequency index which decides the frequency configuration of PSD of road surface $(\omega=2)$.

The road surface roughness is assumed to be a zero-mean stationary Gaussian random process. It can be generated through an inverse Fourier transformation:

$q(t)=\sum_{i=1}^{N} \sqrt{2 S_{q}\left(n_{i}\right) \Delta n} \cos \left(2 \pi n_{k} t+\phi_{i}\right)$,

where $\phi_{i}$ is random phase uniformly distributed from 0 to $2 \pi$.

In this study, typical road surface roughness is adopted according to the standard ISO 8068 [6] and the simulation results of the typical road surface roughness are shown in Fig. 2.

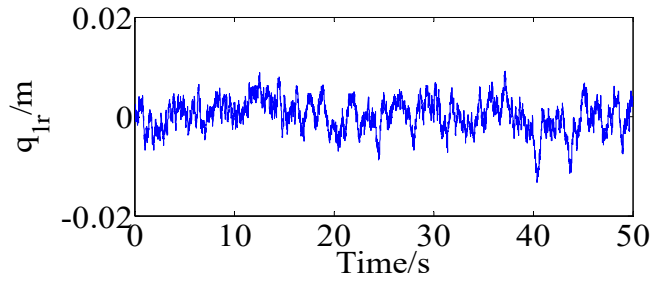

a) Level $\mathrm{B}$

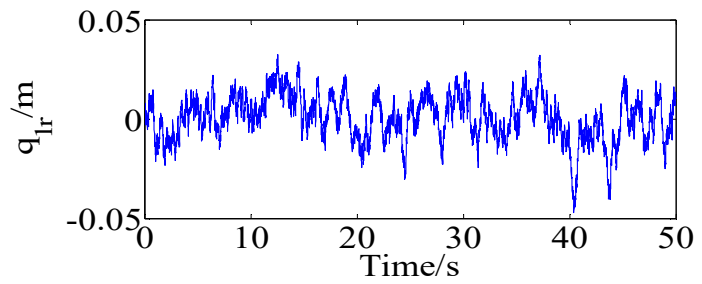

c) Level D

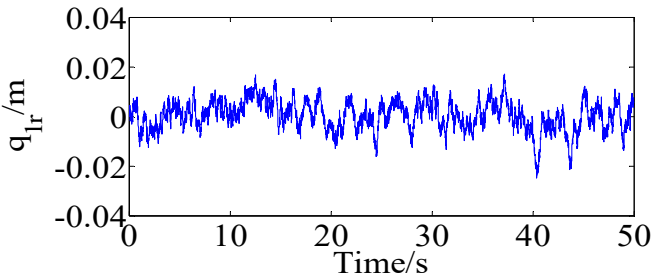

b) Level C

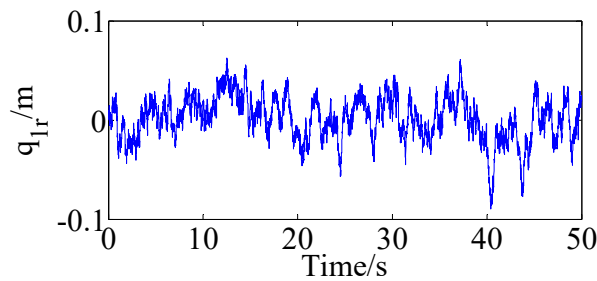

d) Level E

Fig. 2. Typical road surface roughness according to the standard ISO 8068

\section{Road damage criteria}

Road damage criteria are as follows: most of the civil engineering literature uses static vehicle load for design of road surfaces. They have achieved mixed success due to the complex nature of the road damage problem. But the role of vehicle dynamic loads in the road surface design is still not completely known. Some of the major performance criteria considering road damage are based on fourth power law of American Association of State Highway Officials (AASHO) in 1960. Subsequently, other criteria were established in terms of AASHO, such as EC criteria in 1992 and Australia criteria in 1999 [9]. In this study, in order to analyze the influence of semi-trailer truck operating conditions on road surface, dynamic load coefficient (DLC) is chosen as objective function which is defined by a ratio of the root mean square of the vertical dynamic tire force over static load [7, 8], as follows:

$D L C=\frac{F_{T, R M S}}{F_{S}}$

where, $F_{T, R M S}$ is the root mean square of the vertical dynamic tire force and $F_{S}$ is static tire force.

The DLC's value is in range of 0.05 to 0.3 under normal operating conditions. It may reach to the zero when the wheels are moving on a special smooth road or increase up to 0.4 when the tires of the axles spends a significant proportion of their time disconnecting the road surface [8]. 


\section{Results and discussion}

In order to solve the general dynamic differential equation for 5-axle semi-trailer truck which presented in section 2.1 for analyzing the influence of vehicle operating conditions on road friendliness. Matlab/Simulink software is used with a specific set of parameters of vehicle [2] to simulate and define the objective function when vehicle operates under the different conditions.

\subsection{Effect of road surface roughness}

In order to analyze the influence of the road surface roughness on the tire dynamic load, dynamic load coefficient and road -friendliness, five road surface conditions from level A (very good) to level E (very poor) in ISO/TC 80686 have been considered as inputs to the vehicle-road coupled model when vehicle moves with a velocity of $20 \mathrm{~m} / \mathrm{s}$ and fully loaded. The dynamic left tire loads acting on road surface at 2 nd axle and the values of the left tire dynamic load coefficients of 1st axle, 2nd axle, 3rd axle, 4th axle and 5th axle when vehicle moves on five different road surface conditions are shown in Fig. 3 and Fig. 4.

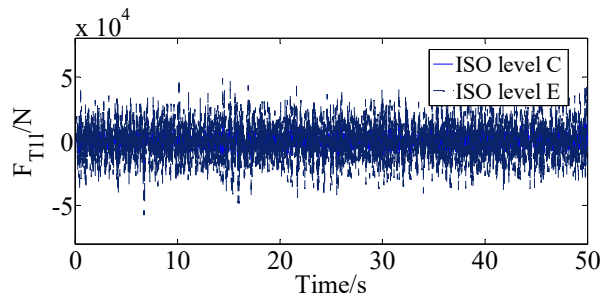

Fig. 3. Dynamic left tire loads acting on road surface at 2 nd axle with two different road conditions

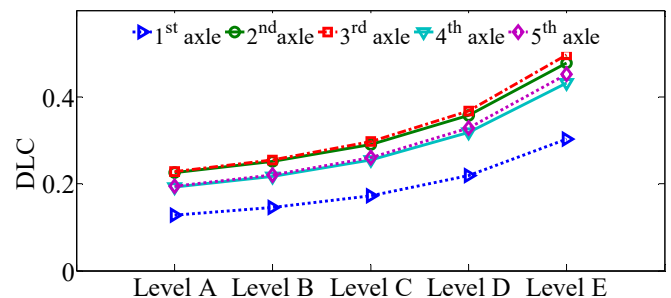

Fig. 4. Effect of road surface roughness

Fig. 3 could be determined the $F_{T 2 l, R M S}$ values of the 2 nd axle when vehicle moves on the average road surface condition (level $C$ ) to very poor road surface condition (level E). The $F_{T 2 l, R M S}$ value of the 2 nd axle increases 3.13 times when the road condition is very poor for the specific case of 5-axle semi-trailer truck with a velocity of $20 \mathrm{~m} / \mathrm{s}$ and full loaded. Fig. 4 shows that the DLC values of the five different axles increase quickly when vehicle moves on the poor road surface conditions and that makes the negative effects on the road surface. When the vehicle changing road surface condition moves on the average road surface condition (level C) to poor road surface condition (level D) and then to very poor road surface condition (level E), the DLC values of the 3 rd axle increase from $23.97 \%$, and $34.88 \%$. Therefore, the road surface condition of level D (the DLC value $\leq 3.0$ ) is chosen as the intervention limit for road surfaces. In this case, traffic management need to intervene quickly to give a safe speed limit for vehicle when it moves on these roads and need to repair the road surface. To improve the safety of movement and reduce the negative impact on the road surface, this study proposes that the speed limit for 5-axle semi-trailer truck is $v_{\max } \leq 12.5 \mathrm{~m} / \mathrm{s}$ for the road surface condition of the ISO level $\mathrm{D}$, $v_{\max } \leq 8.3 \mathrm{~m} / \mathrm{s}$ for the road surface condition of the ISO level E.

\subsection{Effect of vehicle speed}

The vehicle speeds of $5 \mathrm{~m} / \mathrm{s}, 7.5 \mathrm{~m} / \mathrm{s}, 10 \mathrm{~m} / \mathrm{s}, 12.5 \mathrm{~m} / \mathrm{s}, 15 \mathrm{~m} / \mathrm{s}, 17.5 \mathrm{~m} / \mathrm{s}, 20 \mathrm{~m} / \mathrm{s}, 22.5 \mathrm{~m} / \mathrm{s}$, $25 \mathrm{~m} / \mathrm{s}, 27.5 \mathrm{~m} / \mathrm{s}, 30 \mathrm{~m} / \mathrm{s}$ and $32.5 \mathrm{~m} / \mathrm{s}$ were considered to analyze the influence of vehicle speed on the tire dynamic load, dynamic load coefficient and road friendliness when vehicle moves on the road surface condition of the ISO level B and full loaded. The dynamic left tire loads acting on road surface at $3 \mathrm{rd}$ axle and the values of the left tire dynamic load coefficients of 1 st axle, 2 nd axle, 3rd axle, 4th axle and 5th axle when vehicle moves on the different vehicle speed are shown in Fig. 5 and Fig. 6. 
As can be seen from Fig. 5, the $F_{T 3 l, R M S}$ values of the 3rd axle when vehicle moves on the good road surface condition (level B) with $v=10 \mathrm{~m} / \mathrm{s}$ and $v=20 \mathrm{~m} / \mathrm{s}$ are determined by $1533.7 \mathrm{~N}$ and $1958.8 \mathrm{~N}$, respectively and increased by $27.7 \%$. Fig. 6 shows that when vehicle speed value is $v \geq 22.5 \mathrm{~m} / \mathrm{s}$, the DLC values increase the most quickly in the direction of the un-friendly road surface. Therefore, the vehicle speed values $v \leq 22.5 \mathrm{~m} / \mathrm{s}$ is chosen as the road-friendly limit of driving speed for 5-axle semi-trailer truck when vehicle moves on the good road conditions and full loaded.

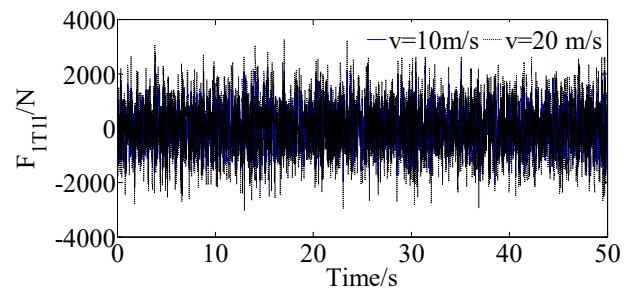

Fig. 5. Dynamic left tire loads acting on road surface at 3rd axle with two different velocity conditions

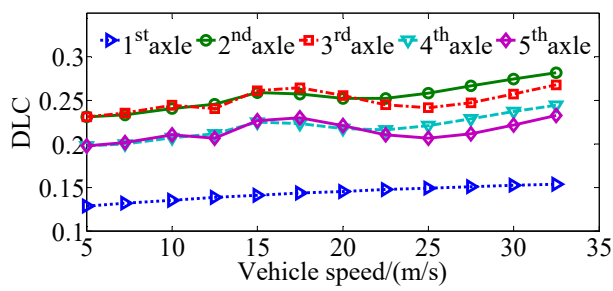

Fig. 6. Effect of vehicle speed

\subsection{Effect of vehicle load}

Vehicle load not only affects the durability of the part of vehicle, but also affects the fatigue life of road surface. In order to the influence of the vehicle load on road surface damage, the load values of 5-axle semi-trailer truck which include $25 \%$ loaded, half loaded, $75 \%$ loaded, fully loaded, over $25 \%$ loaded and over $50 \%$ loaded are discussed when vehicle moves on the road surface condition of the ISO level B at a velocity of $20 \mathrm{~m} / \mathrm{s}$. The dynamic left tire loads acting on road surface at 3rd axle and the values of the left tire dynamic load coefficients of 1st axle, 2nd axle, 3rd axle, 4th axle and 5th axle when vehicle moves under the different vehicle load at the velocity of $20 \mathrm{~m} / \mathrm{s}$ are shown in Fig. 7 and Fig. 8.

From Fig. 7, we can see that the amplitude values of the maximum vertical dynamic left tire force of the 3rd axle when vehicle operates under vehicle load of $50 \%, 100 \%$ and $150 \%$ are determined by $7893.4 \mathrm{~N}, 7827.5 \mathrm{~N}$ and $7459.1 \mathrm{~N}$, respectively and increased by $0.84 \%$ and $4.94 \%$, respectively. Fig. 8 shows that the DLC values of all axles of vehicle increase most quickly when vehicle operates under $25 \%$ loaded condition and half loaded condition which it has impact negatively on road surface and has no benefit to the durability of the part of vehicle and the safe movement of vehicle.

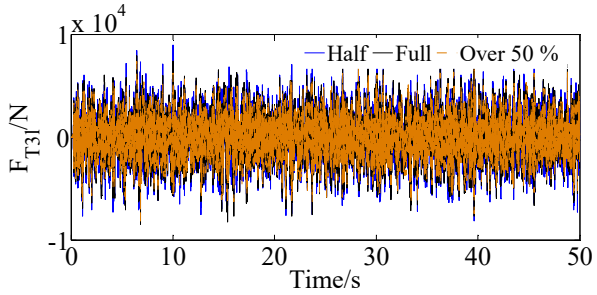

Fig. 7. Dynamic left tire loads acting on road surface at 3rd axle with three different loading conditions

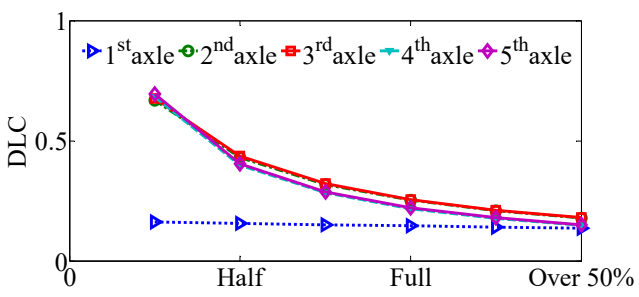

Fig. 8. Effect of vehicle load

\section{Conclusions}

In this study, the influence of the different vehicle operating conditions on the dynamic tire loads and road-friendliness of vehicle using the three-dimensional vehicle-road coupled model which including road surfaces, vehicle speeds, vehicle loads were analyzed comprehensively via the $F_{T, R M S}$ and DLC and the following conclusions can be drawn: 
1) The influence of the road surface roughness and vehicle loads on the tire dynamic load coefficient as well as road friendliness is very obvious. Especially, the DLC values of the 3rd axle increase from $23.97 \%$, and $34.88 \%$ when vehicle moves on three different road conditions with a velocity of $20 \mathrm{~m} / \mathrm{s}$ and fully loaded

2) From the analytical results, the road-friendly limits of driving speeds of vehicle were proposed when vehicle operates under different conditions. Especially, the speed limit for 5-axle semi-trailer truck is $v_{\max } \leq 12.5 \mathrm{~m} / \mathrm{s}$ for the road surface condition of the ISO level D, $v_{\max } \leq 8.3 \mathrm{~m} / \mathrm{s}$ for the road surface condition of the ISO level E.

3) The developed methodology can be used to further study the vehicle-induced road surface response, and the information of the dynamic tire loads will be useful in analyzing the safe movement of the semi-trailer trucks.

\section{Acknowledgements}

The work described in this paper was supported by Thai Nguyen University of Technology for a Scientific Project (Code: T2016-54).

\section{References}

[1] Sun Lijun Structural Behavior Study for Asphalt Pavements. China Communications Press, Beijing, China, 2005.

[2] Le Van Quynh, Zhang Jianrun, Liu Xiaobo, Wang Yuan Nonlinear dynamics model and analysis of interaction between vehicle and road surfaces for 5-axle heavy truck. Journal of Southeast University, Vol. 27, Issue 4, 2011, p. 452-457.

[3] Chen Yikai, He Jie, King Mark, et al Effect of driving conditions and suspension parameters on dynamic load-sharing of longitudinal-connected air suspensions. Science China Technological Sciences, Vol. 56, Issue 3, 2013, p. 666-676.

[4] Lu Yongjie, Yang Shaopu, et al. Numerical and experimental investigation on stochastic dynamic load of a heavy duty vehicle. Applied Mathematical Modeling, Vol. 34, Issue 1, 2010, p. 2698-2710.

[5] Dodds C. J., Robson J. D. The description of road surface roughness. Journal of Sound and Vibration, Vol. 31, Issue 2, 1973, p. 175-183.

[6] ISO 8068 Mechanical Vibration-Road Surface Profiles-Reporting of Measured Data. International Organization for Standardization, 1995.

[7] Cole D. J., Cebon D. Truck suspension design to minimise road damage. The Journal of Automobile Engineering, Vol. 210, 1996, p. 95-107.

[8] Rosnawati Buhari, Munzilah Md Rohani, et al. Dynamic load coefficient of tyre forces from truck axles. Applied Mechanics and Materials, Vol. 405, Issue 408, 2013, p. 1900-1911.

[9] Cebon D. Handbook of Vehicle-Road Interaction. Netherlands Swets and Zetinger Press, Lisse, 1999. 